\title{
Clinical Implications of Psychosocial Factors on Pediatric External Fixation Treatment and Recommendations
}

\author{
Heather M. Richard PsyD, Dylan C. Nguyen MA, John G. Birch MD, FRCS(C), \\ Sandy D. Roland PhD, Mikhail K. Samchukov MD, Alex M. Cherkashin MD
}

Published online: 1 April 2015

(C) The Association of Bone and Joint Surgeons (B) 2015

\begin{abstract}
Background Pediatric limb reconstruction using circular external fixation is a prolonged treatment that interrupts patients' daily function. Patient personality characteristics and expectations may interfere with planned treatment, making complicated medical procedures more challenging. The aims of this study are to identify factors impacting treatment outcome and recommendations for preoperative evaluation and planning.

Questions/purposes (1) Are there group differences between patients with and without a preexisting mental health condition(s) in terms of unplanned reoperations? (2) Does the number of surgical procedures before current external fixator placement correlate with the number of unplanned readmissions, unplanned reoperations, and days spent in circular external fixation? (3) Are there group differences between single- compared with two-parent households in terms of inpatient narcotic doses, length of inpatient stay, number of unplanned readmissions, length of readmission(s), and/or unplanned outpatient clinic visits? (4) Does
\end{abstract}

One or more of the authors (JGB, MKS, AMC), or a member of his or her immediate family, has or may receive payments or benefits, during the study period, an amount of USD 10,000 to USD 100,000, from Orthofix (Lewisville, TX, USA).

All ICMJE Conflict of Interest Forms for authors and Clinical Orthopaedics and Related Research ${ }^{\mathbb{R}}$ editors and board members are on file with the publication and can be viewed on request. Each author certifies that his or her institution approved the human protocol for this investigation and that all investigations were conducted in conformity with ethical principles of research.

H. M. Richard ( $\square$ ), D. C. Nguyen, J. G. Birch,

S. D. Roland, M. K. Samchukov, A. M. Cherkashin

Texas Scottish Rite Hospital for Children, 2222 Welborn Street,

Dallas, TX 75219, USA

e-mail: Heather.richard@tsrh.org patient age at the time of surgery have an impact on treatment duration, postoperative complications, and treatment outcome?

Methods This is a retrospective chart review of pediatric patients who underwent limb reconstruction between 2008 and 2012. Patients with limb length discrepancy $>4 \mathrm{~cm}$ or severe angular deformity and who agreed to intervention were treated with circular external fixation. Sixty-seven patients were included; 16 patients were excluded. Statistical analyses included Pearson $\mathrm{r}$ correlation and t-test.

Results Patients who reported preexisting mental health diagnosis $(13 \%)$ had more unplanned reoperations than patients who did not (no mental health diagnosis; 87\%) (mental health diagnosis $3.4 \pm 10.3$ versus no mental health diagnosis $0.2 \pm 0.5$ reoperation[s], $\mathrm{p}=0.022$ ). Number of previous surgical procedures correlated with number of unplanned reoperations $(r=0.448, p<0.001)$, number of unplanned readmissions $(r=0.375, p<0.001)$, and number of days in an apparatus $(r=0.275$, $\mathrm{p}=0.018$ ). Compared with patients from two-parent households, patients from single-parent households received a greater number of inpatient narcotic doses (singleparent $129 \pm 118$ versus two-parent $73 \pm 109$ doses, $\mathrm{p}=0.039$ ), longer length of inpatient stay (single-parent $73 \pm 63$ versus two-parent $40 \pm 65$ days, $p=0.036$ ) more unplanned readmissions (single-parent $0.4 \pm 0.1$ versus two-parent $0.2 \pm 0.2$ readmission, $\mathrm{p}=0.024$ ), longer hospitalization when readmitted (single-parent $5 \pm 11$ versus two-parent $1 \pm 3 \operatorname{day}(\mathrm{s}), \mathrm{p}=0.025)$, and fewer unplanned outpatient visits (single-parent $0.2 \pm 0.8$ versus two-parent $0.9 \pm 1.1$ visit, $\mathrm{p}=0.005$ ). Apparatus applications with successful outcome had higher average age than those with poor outcome (successful outcome $16 \pm 3$ versus poor outcome $13 \pm 4$ years old, $p=$ 0.011). Age at time of apparatus application correlated with 
number of prescribed antibiotics $(\mathrm{r}=0.245, \mathrm{p}=0.036)$ and number of days in an apparatus $(\mathrm{r}=0.233, \mathrm{p}=$ 0.047).

Conclusions As a result of the inherent challenges of limb reconstruction, surgical candidates should be preoperatively assessed and mitigating psychosocial factors managed to maximize successful treatment outcome. Level of Evidence Level IV, therapeutic study.

\section{Introduction}

Circular external fixation in pediatrics has advantages and disadvantages. The advantages include: axial loading of the long bone segment to allow for better bone formation and consolidation, fixation of small and/or osteopenic bone fragments, high degree of adaptability, and ability to extend the apparatus across joints to address instability or subluxation during lengthening $[18,21,22,29,30,43,50]$. In contrast, the degree of interference with activities of daily living (ie, clothing, mobility), the intimidating nature of the device, and the fastidious attention to soft tissue swelling to prevent contact between rings and the skin are perceived disadvantages. Institutionally, we have seen patients and/or their families experiencing depression, sleep deprivation, inability to function academically, relapse into drug/alcohol abuse, and at least one incident each of pyromania (as an escape mechanism) and maternal abandonment. We have also learned that orthopaedic surgeons are not particularly interested in or the best qualified at delving deeply into preexisting psychosocial issues that can impact positive outcome with our recommended treatments or result in coping mechanism failures under the inevitable stressors prolonged, often painful treatment in children can produce for the patient and family alike. We have therefore learned that it is in all parties' best interest to engage in educated, neutral, "third-party" professional psychosocial screening before initiating these protracted and complex orthopaedic reconstructive procedures.

Limb lengthening and deformity correction using external fixators is a long and complicated process [28]. Successful limb lengthening and reconstruction requires a team approach, because patients undergoing limb lengthening and reconstruction may require assistance with rehabilitation and daily maintenance $[3,4,39,45,58]$. As such, a poor support system and familial and/or environmental problems may compromise postoperative self-care, rehabilitation, and outcome [36, 47, 52]. Undergoing limb lengthening and reconstruction also requires mental stability, resilience, and good coping skills to manage increasing pain, limited mobility, and treatment fatigue [10, 11, 15, 19, 35, 41, 58]. This is crucial, because unaddressed psychological, emotional, and behavioral disturbances have been shown to complicate rehabilitation $[2,20,38,40]$. Furthermore, potential complications (eg, pin site infection, device-related failure, fracture and refracture, delayed union, incomplete arrest/ angular deformity) can make a challenging intervention even more arduous. In fact, past studies have noted complication rates as high as $97 \%$, leading to extended hospital stay, increased outpatient visits, unplanned readmissions and reoperations, and prolonged disruption of normalcy $[1,7,8$, $12,13,15,16,23,54,55]$.

Despite complication rates, contributing factors are not well understood. An interdisciplinary preoperative approach is essential for positive outcomes. Preexisting medical, psychosocial, and environmental challenges such as orthopaedic diagnosis, number of previous operations, age at the time of surgical procedure, presence of mental health symptoms, family system, and pain management impact treatment $[14,20,26,44,53]$. Specifying these factors, elucidating the effects on treatment outcome, and recommendations for implementing presurgical psychological intervention as part of an interdisciplinary treatment planning team are the aims of this study.

We therefore investigated the following specific questions: (1) Are there group differences between patients with and patients without a preexisting mental health condition(s) in terms of unplanned reoperations? (2) Does the number of surgical operations before current external fixator placement correlate with the number of additional unplanned reoperations, unplanned readmissions, and days spent in circular external fixator? (3) Are there group differences between single- and two-parent households in terms of inpatient narcotic doses, length of inpatient stay(s), number of unplanned readmissions, length of readmission stay(s), and/or unplanned outpatient visits? (4) Does patient age at the time of apparatus application have an impact on treatment duration, complications, and outcome?

\section{Patients and Methods}

This is a retrospective chart review of complicating factors affecting outcome of limb lengthening and reconstruction using circular external fixation at a pediatric orthopaedic hospital in Dallas, TX, USA. This treatment was recommended for patients diagnosed with congenital limb inequality, trauma-related acquired deformity and nonunion, hip fusion, equinovarus foot correction, radial deficiency, and knee flexion deformity. Patient medical records were crossreviewed by multiple investigators (HMR, DCN, SDR) to maximize accuracy of collected data. A predetermined list of variables was collected and 
categorized for subsequent data analysis: demographics, mental health status, number of previous surgical operations, type of and reason for treatment, daily inpatient pain medication use, length of inpatient stay, return-toschool rate, number of unplanned outpatient visits, number of unplanned readmissions and reoperations, prescribed medication for sleep disturbance, medical complications, and rate of accomplished treatment goals.

Sixteen patients were excluded from the final list as a result of incomplete medical records, application of intramedullary device, and/or rare and unusual cases of external fixation such as major deformity or infected pseudoarthrosis of the spine. The final patient sample, identified through an in-house Health Information Management system, consisted of 67 patients (35 of 67 [52\%] males and 32 of 67 [48\%] females from 38 of 67 [57\%] two-parent and 29 of 67 [43\%] single-parent households) with an average age of $13 \pm 3$ years old (range, 2-19 years old) at the time of fixator application (Table 1) undergoing 73 separate surgical procedures (17 of 73 [23\%] were treated with femoral fixators, 36 of 73 [49\%] tibial fixators, six of 73 [8\%] upper extremity fixators, eight of 73 [11\%] pelvic fixators, five of 73 [7\%] tibial-foot fixators, and one of 73 [1\%] knee fixator) between 2008 and 2012 for limb reconstruction (22 of 73 [30\%] for lengthening, 42 of 73 [58\%] deformity correction, five of 73 [7\%] hip stabilization, and four of 73 [6\%] bone transport).

Nine (nine of 67 [13\%]) patients reported preexisting mental health diagnosis (three of 67 [5\%] diagnosed with attention deficit hyperactivity disorder, one of 67 [1\%] major depressive disorder, one of 67 [1\%] dissociative disorder, one of 67 [1\%] mental retardation, and three of 67 [5\%] multiple mental health diagnoses), whereas six (six of 67 [9\%]) patients reported new mental health symptoms (four of 67 [6\%] reported symptoms of depression, two of 67 [3\%] anxiety) during the course of treatment. Half of the patient sample (37 of 73 [51\%]) returned to school within 2 weeks after inpatient discharge for 37 of $73(51 \%)$ fixator applications, whereas 36 of 73 (49\%) reported absenteeism greater than 2 weeks. Sleep medication was prescribed during the course of treatment to reduce discomfort and improve sleep for 26 of 73 (36\%) fixator applications.

Selection, transfer, and assessment biases were mitigated by efforts to ensure the patient sample fit study aims, to include all complete medical records within the specified time, and to ascertain that all patients included in the study met surgery candidacy criteria, respectively.

Statistical analyses included measure of central tendency, Pearson $r$ correlation, and t-test. A p value of 0.05 was used to determine statistical significance.

\section{Results}

Of 67 patients included in this study, patients who reported a preexisting mental health diagnosis (nine of 67 [13\%]) had more unplanned surgical procedures than patients who did not (58 of 67 [87\%]) (mental health diagnosis $3.4 \pm 10.3$ reoperations versus no mental health diagnosis $0.2 \pm 0.5$ reoperation, $p=0.022$; Table 2). Findings from this study showed that patients with a preexisting mental health diagnosis experienced more complications than their counterparts, suggesting that all patients should be screened for preexisting mental health symptoms and these symptoms should be well managed before surgery planning.

Fifty seven (57 of 67 [85\%]) patients reported having at least one surgical procedure (average, 3 ; range, 1-16) before fixator application, whereas 10 of $67(15 \%)$ patients reported no previous surgical procedure. Pearson $r$ correlational analysis revealed that the number of previous surgical procedures correlated with the number of unplanned reoperations $(r=0.448, p<0.001)$, the number of unplanned readmissions $(\mathrm{r}=0.375, \mathrm{p}<0.001)$, and the number of days in a fixator $(\mathrm{r}=0.275, \mathrm{p}=0.018$; Table 3). Having a moderate to high number of previous surgical operations may be indicative of a complicated medical condition, and, in this study, patients with higher number of previous surgical operations also had more complications. Each patient's medical history should be reviewed and incorporated into candidacy selection, education, and subsequent surgery planning decisions.

Patients from single-parent households had a greater number of average narcotic doses while inpatient (singleparent $129 \pm 118$ doses versus two-parent $73 \pm 109$ doses, $\mathrm{p}=0.039$ ), longer length of inpatient stay (singleparent $73 \pm 63$ days versus two-parent $40 \pm 65$ days, $\mathrm{p}=0.036$ ), more unplanned readmissions (single-parent $0.4 \pm 0.1$ readmission versus two-parent $0.2 \pm 0.2$ readmission, $\mathrm{p}=0.024)$, longer hospitalization when readmitted (single-parent $5 \pm 11$ days versus two-parent $1 \pm 3$ day, $p=0.025$ ), and fewer unplanned outpatient clinic visits (single-parent $0.2 \pm 0.8$ visit versus two-parent $0.9 \pm 1.1$ visit, $p=0.005$; Table 4) than patients from two-parent households, indicating that patients from singleparent households required more inpatient narcotics, spent more days in the apparatus, and had more complications. Perhaps patients from single-parent homes require more education and social support regarding pain management, postoperative self-care, and rehabilitation.

Seventy-one (71 of 73 [97\%]) surgical procedures had at least one complication: patients received antibiotics at least once for 65 of 73 (89\%) procedures (Type I complication), had an alteration of treatment plan but still achieved treatment goal for 21 of 73 (29\%) procedures (Type II 
Table 1. Demographics $(\mathrm{n}=67)$

\begin{tabular}{|c|c|c|c|c|c|c|}
\hline \multicolumn{4}{|l|}{35 males } & \multicolumn{3}{|l|}{32 females } \\
\hline 15 SPHs & & 20 TPHs & & 14 SPHs & & $18 \mathrm{TPHs}$ \\
\hline 3 no PSs & $12 \mathrm{PSs}$ & 3 no PSs & $17 \mathrm{PSs}$ & 3 no PSs & $11 \mathrm{PSs}$ & 1 no PS \\
\hline
\end{tabular}

$\mathrm{SPH}=$ patients from single-parent household; TPH = patients from two-parent household; no PSs = patient without any previous surgeries; PSs $=$ patients with one or more previous surgeries.

Table 2. Contributory effect of mental health conditions on number of surgery-related outcomes

\begin{tabular}{lllllllll}
\hline Variable & \multicolumn{2}{l}{ MHD $(\mathrm{n}=9 / 67)$} & & \multicolumn{2}{l}{ No MHD $(\mathrm{n}=58 / 67)$} & $\mathrm{p}$ value \\
\cline { 2 - 3 } & Mean \pm SD & $95 \%$ confidence interval & Range & & Mean \pm SD & $95 \%$ confidence interval & Range \\
\hline Number of unplanned surgeries & $3.4 \pm 10.3$ & $0-11.4$ & $0-31$ & & $0.2 \pm 0.5$ & $0.1-0.4$ & $0-2$ & 0.022 \\
\hline
\end{tabular}

MHD = patients who reported preexisting mental health diagnosis(es); no MHD = patients who did not report preexisting mental health diagnosis(es).

Table 3. Correlates of previous surgical procedures with surgery-related outcomes

\begin{tabular}{llr}
\hline Variable & Pearson r & $p$ value \\
\hline Number of unplanned surgeries & 0.448 & $<0.001$ \\
Number of unplanned readmissions & 0.375 & $<0.001$ \\
Number of days in frame & 0.275 & 0.018 \\
\hline
\end{tabular}

Table 4. Contributory effects of household status on surgery-related outcomes

\begin{tabular}{|c|c|c|c|c|c|c|c|}
\hline \multirow[t]{2}{*}{ Variable } & \multicolumn{3}{|c|}{ SPH $(n=29 / 67)$} & \multicolumn{3}{|c|}{ TPH $(\mathrm{n}=38 / 67)$} & \multirow[t]{2}{*}{$\mathrm{p}$ value } \\
\hline & Mean $\pm \mathrm{SD}$ & $95 \%$ confidence interval & Range & Mean $\pm \mathrm{SD}$ & $95 \%$ confidence interval & Range & \\
\hline $\begin{array}{l}\text { Average number of inpatient narcotics } \\
\text { (in doses per inpatient stay) }\end{array}$ & $129 \pm 118$ & $85-173$ & $2-458$ & $73 \pm 109$ & 39-106 & $4-601$ & 0.039 \\
\hline Length of inpatient stay (days) & $73 \pm 63$ & 49-97 & $4-213$ & $40 \pm 65$ & $20-60$ & $2-301$ & 0.036 \\
\hline Number of unplanned readmissions & $0.4 \pm 0.1$ & $0-0.7$ & $0-5.0$ & $0.2 \pm 0.2$ & $0-0.1$ & $0-1.0$ & 0.024 \\
\hline $\begin{array}{l}\text { Length of hospitalization when } \\
\text { readmitted (days) }\end{array}$ & $5 \pm 11$ & $0-9$ & $0-47$ & $1 \pm 3$ & $0-1$ & $0-20$ & 0.025 \\
\hline Number of unplanned outpatient visits & $0.2 \pm 0.8$ & $0-0.4$ & $0-3.0$ & $0.9 \pm 1.1$ & $0.6-1.3$ & $0-4.0$ & 0.005 \\
\hline
\end{tabular}

$\mathrm{SPH}=$ patients from single-parent household; TPH = patients from two-parent household.

complication), did not achieve treatment goal but had no sequelae for 11 of 73 procedures (15\%) (Type IIIA complication), and did not achieve treatment goal and had other sequelae for five of $73(7 \%)$ procedures (Type IIIB complication; Table 5). Procedures with successful outcome (Type I and/or Type II complications only) had a higher average age per group than procedures with poor outcome (Type IIIA and/or Type IIIB complications) (successful outcome $16 \pm 3$ years old versus poor outcome
$13 \pm 4$ years old, $p=0.011$; Table 6). Age at the time of fixator application also correlated with the number of prescribed antibiotics $(\mathrm{r}=0.245, \mathrm{p}=0.036)$ and the number of days in the fixator $(\mathrm{r}=0.233, \mathrm{p}=0.047$; Table 7). Preoperative education and treatment planning as well as perioperative and postoperative support managing treatment challenges and recovery expectations may need to be individualized based on the patient's age and developmental status. 
Table 5. Types of postoperative complications

\begin{tabular}{ll}
\hline Type & Definition \\
\hline Type I & Complications were considered expected/anticipated occurrences and were corrected within treatment plan \\
& No change to original treatment plan \\
& Treatment achieved desired outcome \\
& Example: pin site infection, slight joint contracture resolvable with physical therapy, mild allergic reactions, etc \\
Type II & Complications required modification of treatment plan or development of new treatment plan \\
& Modified (or new) treatment achieved desired outcome \\
Type IIIA & Example: joint contracture requiring intensive physical therapy, delayed consolidation, device-related complications, etc \\
& Complications led to failure to achieve desired outcome \\
Type IIIB & Complications led to failure to achieve desired outcome \\
& New pathology/diagnosis created \\
& Patient's condition is worse than before treatment \\
& Examples: regenerate defect/fracture; joint subluxation/dislocation; severe flexion contracture, etc
\end{tabular}

Table 6. Age difference in treatment outcome

\begin{tabular}{lllllllll}
\hline Variable & \multicolumn{2}{l}{$\mathrm{SO}(\mathrm{n}=57 / 73)$} & & \multicolumn{2}{l}{$\mathrm{PO}(\mathrm{n}=16 / 73)$} & $\mathrm{p}$ value \\
\cline { 2 - 3 } & Mean $\pm \mathrm{SD}$ & $95 \%$ confidence interval & Range & & Mean $\pm \mathrm{SD}$ & $95 \%$ confidence interval & Range \\
\hline Age (years) & $16 \pm 3$ & $14-15$ & $7-19$ & & $13 \pm 4$ & $10-14$ & $2-17$ & 0.011 \\
\hline
\end{tabular}

$\mathrm{SO}=$ patients with successful treatment outcome; $\mathrm{PO}=$ patients with poor treatment outcome.

Table 7. Correlates of age at the time of frame application with surgery-related outcomes

\begin{tabular}{lll}
\hline Variable & Pearson $\mathrm{r}$ & $\mathrm{p}$ value \\
\hline Number of prescribed antibiotics & 0.245 & 0.036 \\
Number of days in frame & 0.233 & 0.047 \\
\hline
\end{tabular}

\section{Discussion}

\section{Background and Rationale}

The external circular fixator is a device involving long and complicated orthopaedic treatment, which has inherent advantages and disadvantages. Limb lengthening and reconstruction requires patients' and families' complete commitment for many months, sometimes up to a year. Such treatment has also been known to have high complication rates, although the contributing factors have not been evaluated. Some factors may be amenable to appropriate presurgical interdisciplinary treatment assessment, planning, and intervention to maximize treatment outcome. Surgeons and patients/families must acknowledge and address the fact that complex reconstructive orthopaedic procedures interfere with activities of daily living, sleep, academic progress, and other family members' obligations. Findings from a non peer-reviewed published work indicated that patients and families experienced significant stress while undergoing extensive, prolonged external fixation treatment [31]. Consequently, professional preoperative assessment of patients being considered for complex limb reconstruction can be beneficial. Anecdotal experience shows it to be of particular value in the presence of preexisting family or personal history of drug and/or alcohol abuse, psychiatric illness, and nonnuclear families. The current study demonstrated similar experience and report, thus reaffirming the value of careful candidacy evaluation and selection before embarking on such treatment courses. 
Table 8. Recommendations for preoperative evaluation $[5,11,17,24,25,27,37,42,46,48,49]$

\begin{tabular}{|c|c|}
\hline Key points & Specific objectives \\
\hline sychiatric symptoms & $\begin{array}{l}\text { Rule out complicating mental health condition(s) } \\
\text { Stabilize mental health condition(s) } \\
\text { Refer for appropriate psychological and psychiatric interventions, if needed } \\
\text { Assess patient and family ability to cope with long-term medical treatment }\end{array}$ \\
\hline Preoperative education & $\begin{array}{l}\text { Assess what patient and family learned from other team members } \\
\text { Provide repeated and consistent education regarding all aspects of treatment } \\
\text { Set realistic expectations }\end{array}$ \\
\hline Pain management & $\begin{array}{l}\text { Refer to patient's previous surgical procedures and related challenges for baseline information } \\
\text { Understand patient's ability to cope with pain and how he or she communicates to medical team and family } \\
\text { Teach pain management strategies, including proper analgesic use, at an age-appropriate level }\end{array}$ \\
\hline Family support & $\begin{array}{l}\text { Verify family's commitment and support to patient } \\
\text { Identify primary caretaker(s) and discharge plan } \\
\text { Teach appropriate responses to patient's pain complaints } \\
\text { Account for other family stressors }\end{array}$ \\
\hline Adherence & $\begin{array}{l}\text { Assess patient's and family's ability to follow directions, maintain appointments, and follow up with scheduled } \\
\text { appointments }\end{array}$ \\
\hline Goals of treatment & Ascertain that patient and family goals are the same as the medical team's goals, including expectation of setbacks \\
\hline Logistics & $\begin{array}{l}\text { Evaluate potential interferences to long-term treatment such as work, school, and siblings } \\
\text { Assist with planning and accommodations }\end{array}$ \\
\hline Sleep hygiene & $\begin{array}{l}\text { Refer to patient's previous surgical procedures and related challenges for guidelines } \\
\text { Understand patient's preexisting sleep schedule and how treatment might interfere with sleep habits } \\
\text { Teach age-appropriate sleep hygiene and habits }\end{array}$ \\
\hline
\end{tabular}

This study identified group differences between patients with and without a preexisting mental health condition, a positive correlation between the number of previous surgical procedures and unplanned reoperations, unplanned admissions, and days in the external fixator. It also demonstrated group differences between pediatric patients from single- and two-parent households as it relates to inpatient narcotic doses, length of inpatient stay(s), number of unplanned readmissions, length of readmission stay(s), and/or unplanned outpatient visits. Lastly, the impact of age at the time of external fixator placement on treatment duration, complications, and outcome was evaluated.

There are limitations and biases in this study. This includes selection bias, because only patients who underwent limb lengthening and reconstruction with circular external fixation were sampled and included for retrospective data analysis. Researchers specifically aimed to examine preexisting factors that complicated outcome in patients who had already completed medical treatment using external fixators. It is unknown how many patients were considered for circular external fixators but did not undergo treatment. Transfer bias also exists. Sixteen patients were excluded from the final patient sample as a result of rare and unusual cases of external fixation, intramedullary lengthening, or incomplete medical records. It is unclear how inclusion of patients with missing medical records would have altered these findings. No patient was lost before minimum followup. Assessment bias is another bias potentially present in this study. Specific criteria based on the operating surgeons' expertise in this area were set for patient selection for surgical intervention. Those criteria included: a limb length discrepancy of $4 \mathrm{~cm}$ or greater, severe limb or angular deformity with either shortening or soft tissue compromise that jeopardize acute correction options, and agreement of both the patient and family to undergo limb lengthening and deformity by circular external fixation. Patients included in this study met the clinical indications of limb lengthening and deformity correction and agreed to proceed. This study was designed to demonstrate associations of potential factors as it affects treatment.

For patients undergoing limb lengthening and reconstruction, having a mental health condition positively correlated with unplanned reoperations, making a challenging medical intervention with a psychiatrically fragile child more complicated. Other research has indicated that the presence of elevated psychological symptoms may complicate treatment and may alter outcome [24, 25, 27, $32,42,56]$. That is not to say that those with a mental health diagnosis should not be considered for elective limb lengthening and reconstruction surgery. Rather, all patients 
should be screened for the presence of psychiatric symptoms and appropriate management of these symptoms should be required before planning surgical intervention of this magnitude (Table 8). As the lead team member, the surgeon should be aware of the patient's preexisting mental health condition and the potential impact during treatment.

Many patients in our study sample had surgical operations before circular external fixator placement during this time period. The number of surgical operations before apparatus placement correlated with the number of unplanned readmissions, reoperations, and length of time in the device. It is likely that an overall complicated medical history may contribute to challenges during extended intervention [32, 49, 51]. Surgeons should, therefore, account for this when considering appropriate patients for external fixation by properly educating patients and families about potential increased risk of complications and expectations throughout treatment (Table 8).

Parental marital status also demonstrated an impact on outcomes. Patients from single-parent households required greater number of narcotics, longer inpatient stay, and more unplanned readmissions. Patients from two-parent households, however, had more unplanned outpatient clinic visits. Perhaps the inherent stress of a single-parent household may contribute to a greater allocation of postoperative care to the child, thus requiring extended hospitalization, more support from the medical team, and reliance on medication for pain management. Conversely, patients from two-parent households have greater presumed family support, which may include a stay-at-home parent who is overly attentive to perceived changes and inclined to seek medical attention. The dynamics of a patient's household seemed to play a role in postoperative management in our study, which is consistent with existing literature examining home life, family support, and the quality of home care provided after a medical procedure $[9,11,37,57]$. These findings support the importance of preoperative assessment of social support and teaching pain management strategies to patients and caregivers (Table 8).

Older patients achieved treatment goal with fewer complications compared with younger patients. Older patients also spent longer time in the apparatus and required a greater number of antibiotics. Many factors could have accounted for these findings, including medical indication for external fixation, goal(s) of treatment, knowledge of and adherence to postoperative care, and developmental stage as it impacts physical growth, cooperation, and postoperative self-care [33, 41, 57]. Appropriate education regarding these findings will establish reasonable expectations of treatment duration and potential challenges.

Although many patients did not report a mental health diagnosis before treatment, $9 \%$ developed symptoms of anxiety or depression during treatment. Whether the patients had a predisposition to psychological symptoms before apparatus placement is hard to say. It is likely that the stress, limitations, and pain of prolonged external fixation were beyond the coping abilities of these patients and contributed to symptom onset [34]. Our study also showed that more than half of patients undergoing limb lengthening and reconstruction returned to school within a 2-week period. Current literature on this topic is limited; therefore, it is unclear whether our study patients had a high or low return-to-school rate. Additionally, one-third of our patients reported sleep disturbance postoperatively. This is consistent with other studies, which noted moderate to high rates of patient-reported sleep difficulty after major surgical intervention [6]. Still, poor sleep quality has been shown to affect healing and recovery and therefore should be managed to maximize outcome (Table 8).

Ensuring proper understanding of medical treatment and goals, cooperation, familial agreement, and other relevant psychosocial factors is imperative for successful outcomes when managing limb length discrepancy or deformity in the pediatric population and perhaps with adult patients as well. Preoperative psychological intervention as part of an interdisciplinary team and identification of barriers are keys to choosing the appropriate surgical candidate for limb lengthening and reconstruction intervention. It is essential that the patient, family, and involved medical staff work as a collaborative team with the same goals of treatment established before fixation placement as well as reasonable expectations of challenges and duration of medical intervention. Patients who have the identified factors are shown to have a more complicated treatment course. It is therefore recommended that if not all patients are screened preoperatively, then at least those who have a preexisting mental health condition and psychosocial challenges should undergo appropriate management before planning the surgical procedure. An interdisciplinary, presurgical, proactive approach to patient education, selection, and treatment should be an integral part of treatment planning for a successful outcome in this population. Understanding the strengths and barriers of individual surgical candidates may ultimately improve patient care by reducing complications, readmissions, narcotic dosages, unplanned reoperations, and decreasing length of stay. Research evaluating long-term, quality of life, and function is underway at our institution. Validating preoperative, interdisciplinary intervention will also be an important future direction. Psychological preoperative and posttreatment assessment will likely better inform pediatric orthopaedic surgeons about which factors to consider when selecting surgical candidates and, perhaps, mitigate some of the complications and challenges during treatment. 


\section{References}

1. Antoci V, Ono CM, Antoci V Jr, Raney EM. Pin-tract infection during limb lengthening using external fixation. Am J Orthop. 2008;37:E150-154.

2. Bair MJ, Wu J, Damush TM, Sutherland JM, Kroenke K. Association of depression and anxiety alone and in combination with chronic musculoskeletal pain in primary care patients. Psychosom Med. 2008;70:890-897.

3. Barker KL, Lamb SE, Simpson HR. Recovery of muscle strength and power after limb-lengthening surgery. Arch Phys Med Rehabil. 2010;91:384-388.

4. Coglianese DB, Herzenberg JE, Goulet JA. Physical therapy management of patients undergoing limb lengthening by distraction osteogenesis. J Orthop Sports Phys Ther. 1993;17:124-132.

5. Cremeans-Smith JK, Millington K, Sledjeski E, Greene K, Delahanty DL. Sleep distruptions mediate the relationship between early postoperative pain and later functioning following total knee replacement surgery. J Behav Med. 2006;29:215-222.

6. Cronin AJ, Keifer JC, Davies MF, King TS, Bixler EO. Postoperative sleep disturbance: Influences of opioids and pain in humans. Sleep. 2001;24:39-44.

7. Dahl MT, Gulli B, Berg T. Complications of limb lengthening: A learning curve. Clin Orthop Relat Res. 1994;301:10-18.

8. Danziger MB, Kumar A, DeWeese J. Fractures after femoral lengthening using the Ilizarov method. $J$ Pediatr Orthop. 1995;15:220-223.

9. Dunbar SB, Clark PC, Quinn C, Gary RA, Kaslow NJ. Family influences on heart failure self-care and outcomes. J Cardiovasc Nurs. 2008;23:258-265.

10. Eckhouse-Ekeberg DR. Promoting a positive attitude in pediatric patients undergoing limb lengthening. Orthop Nurs. 1994;13: $41-49$.

11. Edwards PW, Zeichner A, Kuczmierczyk AR, Boczkowski J. Familial pain models: the relationship between family history of pain and current pain experience. Pain. 1985;21:379-384.

12. Eldridge JC, Bell DF. Problems with substantial limb lengthening. Orthop Clin North Am. 1991;22:625-631.

13. Emara KM, Khames A. Functional outcome after lengthening with and without deformity correction in polio patients. Int Orthop. 2008;32:403-407.

14. Frierson RL, Lippmann SB. Psychiatric consultation for acute amputees: report of a ten-year experience. Psychosomatics. 1987;28:183-189.

15. Garcia-Cimbrelo E, Olsen B, Ruiz-Yague M, Fernandez-Baillo N, Munuera-Martinez L. Ilizarov technique: results and difficulties. Clin Orthop Relat Res. 1992;283:116-123.

16. Glorion C, Pouliquen JC, Langlais J, Ceolin JL, Kassis B. Femoral lengthening using the callotasis method: study of the complications in a series of 70 cases in children and adolescents. J Pediatr Orthop. 1996;16:161-167.

17. Gloss SJ. Post-operative patient's view on sleep, pain and recovery. J Clin Nurs. 1992;1:83-88.

18. Green SA. Ilizarov method. Clin Orthop Relat Res. 1992;280: $2-6$.

19. Guichet JM, Spivak JM, Trouilloud P, Grammont PM. Lower limb-length discrepancy: an epidemiologic study. Clin Orthop Relat Res. 1991;272:235-241.

20. Hrutkay JM, Eilert RE. Operative lengthening of the lower extremity and associated psychological aspects: the Children's Hospital experience. J Pediatr Orthop. 1990;10:373-377.

21. Ilizarov GA. The tension-stress effect on the genesis and growth of tissues: Part I. The influence of stability of fixation and softtissue preservation. Clin Orthop Relat Res. 1989;238:249-281.
22. Ilizarov GA. The tension-stress effect on the genesis and growth of tissues: Part II. The influence of the rate and frequency of distraction. Clin Orthop Relat Res. 1989;239:263-285.

23. Jones DC, Moseley CF. Subluxation of the knee as a complication of femoral lengthening by the Wagner technique. $J$ Bone Joint Surg Br. 1985;67:33-35.

24. Junge A, Dvorak J, Ahrens S. Predictors of bad and good outcomes of lumbar disc surgery: A prospective clinical study with recommendations for screening to avoid bad outcomes. Spine. 1995;20:460-468.

25. Kain ZN, Mayes LC, Caldwell-Andrews AA, Karas DE, McClain BC. Preoperative anxiety, postoperative pain, and behavioral recovery in young children undergoing surgery. Pediatrics. 2006; 118:651-658.

26. Kerper LF, Spies CD, Lossner M, Salz AL, Tafelski S, Balzer F, Weiss-Gerlach E, Neumann T, Lau A, Glaesmer H, Brahler E, Krampe H. Persistence of psychological distress in surgical patients with interest in psychotherapy: results of a 6-month followup. PLoS One. 2012;7:e51167.

27. Keicolt-Glaser JK, Page GG, Marucha PT, MacCallum RC, Glaser R. Psychological influences on surgical recovery: perspective from psychoneuroimmunology. Am Psychol. 1998;53: $1209-1218$

28. Lie CW, Chow W. Limb lengthening in short-stature patients using monolateral and circular external fixators. Hong Kong Med J. 2009;15:280-284.

29. Littlewood R. The benefits and risks of the ilizarov technique for limb reconstruction Am J Orthop Surg. 2007;2:253-264.

30. Matsubara H, Tsuchiya H, Sakurakichi K, Watanabe K, Tomita K. Deformity correction and lengthening of lower legs with an external fixator. Int Orthop. 2006;30:550-554.

31. Morton AA. Psychological considerations in the planning of staged reconstruction in limb deficiencies. In: Herring JA, Birch JB, eds. The Child with a Limb Deficiency. $1^{\text {st }}$ ed. Rosemont, IL, USA: American Acad of Orthopaedic Surgeons; 1998:195-205.

32. Mudge AM, Kasper K, Clair A, Redfern H, Bell JJ, Barras MA, Dip G, Pachana NA. Recurrent readmissions in medical patients: a prospective study. J Hosp Med. 2011;6:61-67.

33. Mulhern RK, Kepner JL, Thomas PR, Armstrong FD, Friedman HS, Kun LE. Neuropsychologic functioning of survivors of childhood medulloblastoma randomized to receive conventional or reduced-dose craniospinal irradiation: a Pediatric Oncology Group study. J Clin Oncol. 1998;16:1723-1728.

34. Nickinson RS, Board TN, Kay PR. Post-operative anxiety and depression levels in orthopaedic surgery: a study of 56 patients undergoing hip or knee arthroplasty. J Eval Clin Pract. 2009;15: 307-310.

35. Niemela BJ, Tjernstrom B, Andersson G, Wahlsten VS. Does leg lengthening pose a threat to a child's mental health? An interim report one year after surgery. J Pediatr Orthop. 2007;27: 611-617.

36. Okkonen E, Vanhanen H. Family support, living alone, and subjective health of a patient in connection with a coronary artery bypass surgery. Heart Lung. 2006;35:234-244.

37. Okoro T, Sell P. The prediction of outcome in somatised patients undergoing elective lumbar surgery. J Bone Joint Surg Br. 2009; 91:517-521.

38. Pless IB, Nolan T. Revision, replication and neglect: research on maladjustment in chronic illness. $J$ Child Psychol Psychiatry. 1991;32:347-365.

39. Ramaker RR, Lagro SW, van Roermund PM, Sinnema G. The psychological and social functioning of 14 children and 12 adolescents after Ilizarov leg lengthening. Acta Orthop Scand. 2000; 71:55-59. 
40. Robinson KE, Gerhardt CA, Vannatta K, Noll RB. Parent and family factors associated with child adjustment to pediatric cancer. J Pediatr Psychol. 2007;32:400-410.

41. Rogers LC, Bevilacqua NJ, Frykberg RG, Armstrong DG. Predictors of postoperative complications of Ilizarov external ring fixators in the foot and ankle. J Foot Ankle Surg. 2007;46:372-375.

42. Rosenberger PH, Kokl P, Ickovics J. Psychosocial factors and surgical outcomes: an evidence-based literature review. $J \mathrm{Am}$ Acad Orhtop Surg. 2006;14:397-405.

43. Sabharwal S, Green S, McCarthy J, Hamdy RC. What's new in limb lengthening and deformity correction. J Bone Joint Surg Am. 2011;93:213-221.

44. Sarwer DB, Wadden TA, Fabricatore AN. Psychosocial and behavioral aspects of bariatric surgery. Obes Res. 2005;13:639-648.

45. Simard S, Marchant M, Mencio G. The Ilizarov procedure: limb lengthening and its implications. Phys Ther. 1992;72:25-34.

46. Simpson T, Lee ER, Cameron C. Patients' perceptions of environmental factors that disturb sleep after cardiac surgery. Am J Crit Care. 1996;5:173-181.

47. Skolasky RL, Mackenzie EJ, Wegener ST, Riley LH 3rd. Patient activation and adherence to physical therapy in persons undergoing spine surgery. Spine. 2008;33:E784-791.

48. Solowiej K, Mason V, Upton D. Review of the relationship between stress and wound healing: Part 1. J Wound Care. 2009;18:357-366.

49. Spengler DM, Freeman C, Westbrook R, Miller JW. Low-back pain following multiple lumbar spine procedures: failure of initial selection? Spine. 1980;5:356-360.

50. Spiegelberg B, Parratt T, Dheerendra SK, Khan WS, Jennings R, Marsh DR. Ilizarov principles of deformity correction. Ann $R$ Coll Surg Engl. 2010;92:101-105.
51. Tsuchihashi M, Tsutsui H, Kodama K, Kasagi F, Setoguchi S, Mohr M, Kubota T, Takeshita A. Medical and socioenvironmental predictors of hospital readmission in patients with congestive heart failure. Am Heart J. 2001;142:E7.

52. van den Akker-Scheek I, Stevens M, Spriensma A, van Horn JR. Groningen Orthopaedic Social Support Scale: validity and reliability. J Adv Nurs. 2004;47:57-63.

53. van Hout GC, Verschure SK, van Heck GL. Psychosocial predictors of success following bariatric surgery. Obes Surg. 2005; $15: 552-560$.

54. Vargas Barreto B, Caton J, Merabet Z, Panisset JC, Pracros JP. Complications of Ilizarov leg lengthening: a comparative study between patients with leg length discrepancy and short stature. Int Orthop. 2007;31:587-591.

55. Velazquez RJ, Bell DF, Armstrong PF, Babyn P, Tibshirani R. Complications of use of the Ilizarov technique in the correction of limb deformities in children. J Bone Joint Surg Am. 1993;75: $1148-1156$.

56. Volz A, Schmid JP, Zwahlen M, Kohls S, Saner H, Barth J. Predictors of readmission and health related quality of life in patients with chronic heart failure: a comparison of different psychosocial aspects. J Behav Med. 2011;34:13-22.

57. Wysocki T, Taylor A, Hough BS, Linscheid TR, Yeates KO, Naglieri JA. Deviation from developmentally appropriate selfcare autonomy: association with diabetes outcomes. Diabetes Care. 1996;19:119-125.

58. Young N, Bell DF, Anthony A. Pediatric pain patterns during Ilizarov treatment of limb length discrepancy and angular deformity. J Pediatr Orthop. 1994;14:352-357. 